\title{
MODERN STUDENTS' MENTAL REPRESENTATIONS OF SUCCESS
}

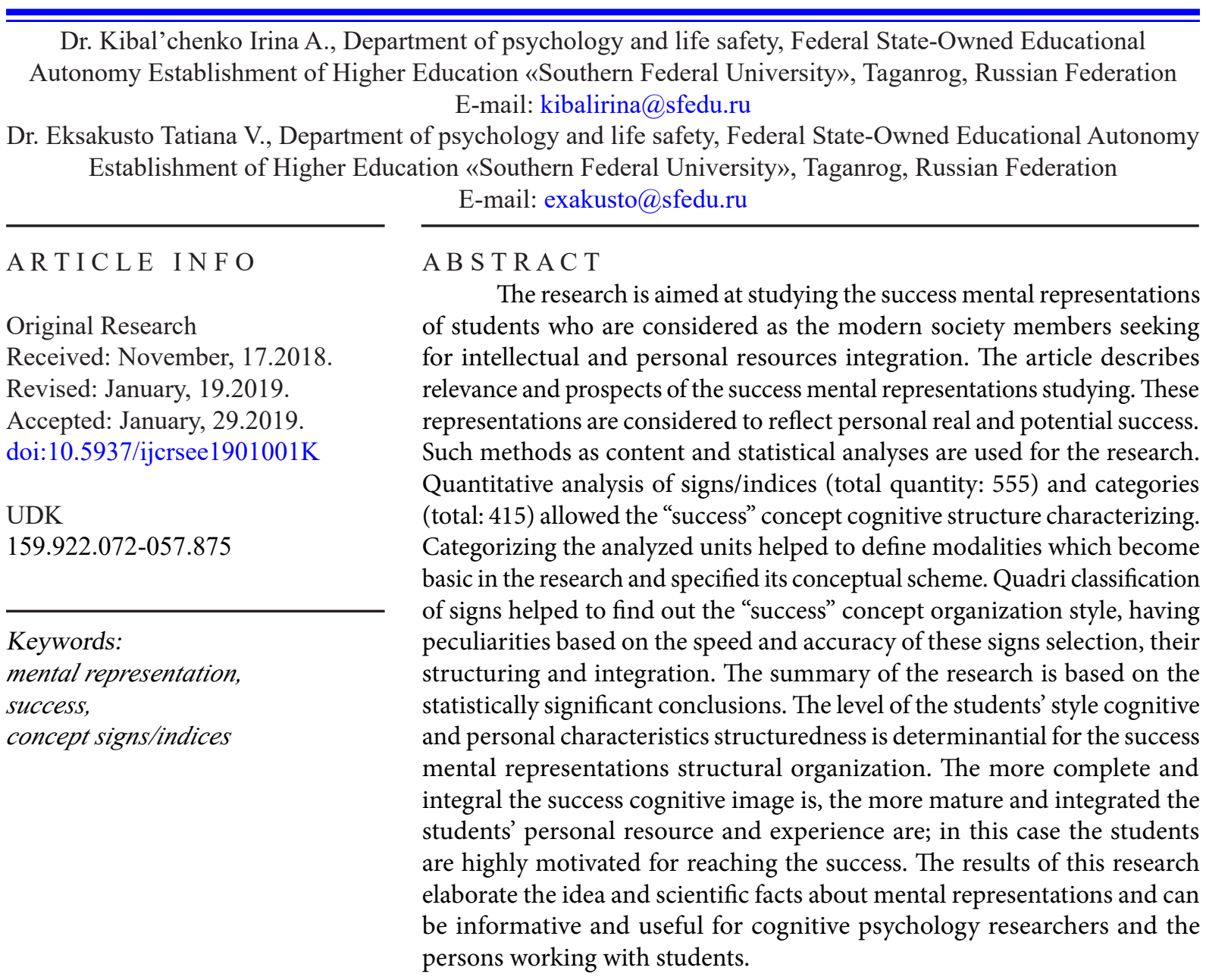

(C) 2019 IJCRSEE. All rights reserved.

\section{INTRODUCTION}

Successful representative of modern society is the person who's intellectual and personal resource is a consistent integrated system supporting person's psychological resistance and stability, ability to counter exogenous adverse effects and/or negative impact. This resource gives the person an opportunity

Corresponding Author

Dr. Kibal'chenko Irina A., Department of psychology and life safety, Federal State-Owned Educational Autonomy Establishment of Higher Education «Southern Federal University», Taganrog, Russian Federation, E-mail: kibalirina@sfedu.ru

This work is licensed under a Creative Commons Attribution - NonCommercial - NoDerivs 4.0. The article is published with Open Access at www.ijcrsee.com to choose the way of self-development and self-improvement in case of solving real situations and problems in life. The person is studied and defined as a subject of life experience (beginning with anticipation processes to selfactuating ones in particular behavioral models and actions), i.e. personal success is one of the most important predictors of the person's future. At the same time the most important factor here is the person's understanding of "own success", his/her success mental representations features and their influence on personal activity. Nowadays, the person him/herself is in need of being successful (as it provides selfconfidence, self-realization, personal growth), as well as the society in general needs separate persons to be successful. All these facts show the relevance of problems connected with the success and successful personality mental representations.

Having analyzed modern researches 
on the problems of "personality success" we can make several conclusions. First of all, the success is often considered as the social and psychological characteristic reflecting person's being satisfied with the process and the results of own life, being focused on success and having socially recognized achievements (Tugusheva, 2008). Secondly, it is identified by many variables (from objective and historical variables to subjective and psychological ones) including the level of personal development, social and individual identity (the system of self-perception, person's realizing the concepts of his/her opportunities and abilities) and helps person to create individual life scenarios, make professional and personal choices in accordance with peculiar life circumstances (Androsenko, 2013). Thirdly, the success has the so called "nuclear structure" consisting of such personal qualities as the ability to compare desires with the opportunities; self-efficacy; importance and value of trust; ability to empathize with surrounding people; ability to estimate and plan the efficiency of the future activity from the perspec-tive of individual events assessment, etc. (Thompson, 2004). Fourthly, success gives an impetus to person's definite professional activity, making person pay attention to the objects important for this activity and life in general; has an influence on choosing favorable and realistic behavioral pattern and vary depending on social experience and person's reaction on social conditions. (Shkherbakova, Tamaskhanova, Klad'ko, 2015; Andrianova, Tarasova, Pecherkina, 2018). Fifthly, it is characterized by a clear semantic field including objective signs such as work, family, health, education, etc., subjective ones such as singlemindedness, sociability, will activity, etc., as well as existential signs: self - actuating, self - fulfillment, self - sufficiency, etc. (Androsenko, 2013; Nanay, 2013). Finally, the success has an impact on individuality formation in general as well as on formation of personal attitudes, self-identification, aspiration level, motivation in particular (however, a reverse influence of the abovementioned variables can be observed in a process of success notion representation system forming) (Low, Overall, Hammond, Girme, 2017; Kishtimova, 2013).

A number of researches reflect outstanding data on different types of success (educational, adaptational, sports, social, professional) correlation with such variables as motivation, intellectual and personal resources, cooperation with other people, self-control, informative activity, etc. Such authors as
Kibal'chenko I. A., Eksakusto T. V. show (on the example of entrepreneurs) that the success of the entrepreneur as a subject of professional activity depends on his/her ability to act analytically, to give an appropriate assessment to any problem and its reasons, to choose necessary actions to solve the problem; to plan activity and to develop strategies for achieving peculiar goals (Welsch, Zimmer, 2018) as well as on such personal characteristics as intellectual and intelligence development correlation with the carried-out activity.

Some researchers empirically prove that having success in educational activity depends on the high level of informative development (i.e. open informative position, cognitive interest, mental maps) (Brigley, 2018) as well as on students being highly motivated, calm and unimpulsive, being able to control and regulate themselves (coping with emotional stress). Such factors as self-motivation, academic self-efficiency, self-control and being satisfied with the training course chosen are of great value for students' orientation and being successful while studying at an educational establishment (Van Rooij, Jansen, and Vande Grift, 2018). At the same time, gifted students who study special programs (for gifted students) are characterized by specific personal and intellectual features, show high social and economic success in further life, including successful graduating from colleges and being successful in their professions (Welsch, Zimmer, 2018).

It is also noted that person's having clear intentions (ideas on simple plans implementation and particular behavior and activity necessary for that in the set conditions) leads to moderate and considerable improvements in achieving the goals that can be used for obtaining the forecasts concerning success in achieving various purposes and goals in future (Pirolli, et al, 2017). Psychological features of people have an in-fluence on success of some special skills development (e.g. people going in for mountain skiing) and sports success in general: there is a positive correlation between young male skiers' self-efficiency and success and inverse back couplingbetween young female skiers' fear and high sports results (Cigrovski, Radman, Konter, 2018). Social success (inter-personal relations efficiency) is connected with such variables as: ability to distinguish and interpret poses, gestures, partner's spatial orientation, his communicative abilities, etc. (Bracci, Caramazza, Peelen, 2018). Partners' mutual understanding based on interoceptive awareness, self-concept and 
perception of others is important for successful communication and interaction (Palmer, and Tsakiris, 2018).

The results of the theoretical analysis point us toward the following conclusion: there is a big range of variables correlating with "personal success". At the same time, the analysis of the existing researches on success showed that there is some dichotomy: on the one hand, a large number of factors, criteria, variables defining success, its contents and realization conditions are revealed. On the other hand, nowadays the number of researches aimed at individual resource value definition, "success" mental representation (exemplified by separate individual persons) as the necessary factor for personal achievements are not enough for making exact conclusions but some researches show direct or indirect connection of success and mental representations.

It is possible to assume that each person possesses a unique and individual complex of success mental representations. These representations set the action procedures, i.e. help to reproduce operational knowledge in personal consciousness which provides efficiency (success) in the set circumstances. In other words, success mental representations can act as the reflection of real and potential success of any person. Within this framework, the problem of studying mental representations having influence on our thinking and actions is of great importance.

The problem of mental representations has been one of the most topical for cognitive psychologists for the last decades. If summing up the psychologists' experience in mental representations studying, it should be noted that the "mental representation" is defined as some "operational form" of mental experience which can vary/be transformed in a situation changing process and a so called person's "intellectual contribution". It is also considered to be rather specific, detailed picture of the set reality.

Numerous researches show the following features of mental representations: they exist in the form of complete units and cannot be characterized by the clear invariable set boundaries (because human experience is subjective); they are verbalized by means of different verbal forms (semantic units) and are continuously reproduced structures corresponding to changes in the environment. This fact helps person to adapt to the environment by means of information control (Tarmaeva, 2010). Mental representations have a level organization; they depend on the activity pur- poses; are the elements of the view of life and are connected with the previous experience (Tsimbalyuk, 2011). They can also be considered as a process (reflections, representations), i.e. the way of reality learning and perception as well as the result of this learning and perception (particular experience description within the world view); their structure includes associative, estimated, conceptual and figurative components (Prokhorov, Alekseeva, 2017). Mental representations are of great importance for studying those mental processes and states which are subjective (subjective experience), i.e. processes and states having no equivalents in objective material world (Prokhorov, Alekseeva, 2017). Researches based on the abovementioned ideas show that studying the processes interaction from the point of view of "ascending" and "descending" movement in hierarchical semiotics field (mental representations field) is necessary for learning process modeling and formation of person's ideas on him/herself and the world in general (Kuvich, Perlovsky, 2013; De Haan, Smit, Van der Stigchel, 2018). Such hierarchical organization of mental representations is considered in the context of psychological well-being ensuring and personal behavior correcting. It is revealed that in many cases, higher level of personal wellbeing and success is caused by high-level structures of mental representations (abstract, global, coherent) integration (Horvath, 2018).

It is also found out that in any situation of life (especially in emotionally significant ones) person makes its semantic assessment and declares peculiar attitude to it. An image of each life situation has a certain rank in subjective view of the world and is associated with certain mental states. The associative unity of mental states and situations is formed and fixed in a process of life activity. It reflects past subjective experience (Prokhorov, 2016).

So, mental representations reflect the world in all its forms and refract through identity of the subject him/herself; they become those important indicators which can predict success of the subject. At the same time, it is necessary to emphasize that the construct of success mental representations and their objective signs (semantic field, type, particularity/non-specificity of figurative schemes, modalities quantity and content, etc.) is developed insufficiently.

It is possible to assume that the success mental representations are determined by cognitive and personal features. The style of the subject (i.e. cognitive style, style of activity, 
behavioral style, style of self-control, coping style) is one of the variables specifying the success mental representations (Kholodnaya, 2004; Beeftink et al, 2012), etc. The researches by Gervais, J., \& Cossette, P. show that it is important to create cognitive maps (ways, routes, lines of environment elements cooperation and interrelations as the instruments of knowledge management) for effective and successful interorganizational communication (ICS); these cognitive maps can be useful for the persons interested in this problem. As well, we found similarities and differences between cognitive maps of the employees' interorganizational communication success; it can be connected with their own styles of the activity organizing (Gervais, J. and Cossette, P., 2007).

Another research proves that the affective and cognitive style of mental representations provides success/efficiency of the relations in the system "Me - Another person". It is shown that the low level of success representations differentiation and integration is expressed in communicating by using simple abrupt and even affectively polarized characteristics for describing other people; mental representations are influenced by affective states, empathy and self-understanding weakness (Korshunova, 2005).

The carried-out analysis showed that the subject's mental representations are widely studied in general, whereas the success mental representations, students' psychological states and success perceptions structure are still understudied. A number of problems are found:

1) on the one hand, semantic field of the "success" concept is accurately defined, on the other hand, its cognitive structure (cognitive signs) in case of different understanding of this concept by students with different cognitive complexity is still not studied enough;

2) the structure of mental representations (its hierarchy, multidimensionality) is described, but those structural features which cause the subject's success are not defined;

3 ) a big range of variables defining success are found out, but connection between the success and person's intellectual resource, cognitive maturity are not studied;

4) researchers describe the influence of success on person's (as well as personal attitudes and self-actualization) formation and development in general, but the role of the success mental representations in formation of person's ideas on him/herself and the world (as a predictor of intellectual and personal development) and in knowledge process model- ing and development is not clear.

So, mental representations - structures, relevant intellectual images, semantic units describing students' experience within the frames of their success acceptance are the subjects of our research. We are aimed at finding answers to the following questions: what features (style, structural, level, etc.) define the subject's system of the success mental representations; connection between cognitive maturity and personal success (potential and real); which structural characteristics of the success mental representations help person to move forward, have an accurate, differentiated and systematical view of the success, which ones prevent to plan the activity, to see the purposes accurately, reduce personal success and quality of life in general.

The results received will allow understanding features of the success representations, their cognitive structure, generality degree, intelligence from the point of view of students' personal experience. Studying the students' understanding of success, their potential and real opportunities is of great importance for subject's intellectual and personal resource, achievements and cognitive maturity analysis. These factors determine effective development of our society.

\section{MATERIALS AND METHODS}

Basic methods used in our research are as follows:

Content analysis was used for studying basic tendencies in students' "success" concept semantic content understanding.

Factor analysis was used to define the structure of the success mental representations in groups of students with different values of the success basic characteristics as well as to define style structures in groups of students with different success mental representations structures.

Kruskal-Wallis' nonparametric statistical criterion $\mathrm{H}$ was used to find out differences of groups in style characteristics, generality levels and experience structure types; Fisher's angular transformation helped to compare the results of previous tests according to the frequency of "success" concept cognitive content and its modalities occurrence.

T. Ehlers' questionnaire "Motivation to success" helped to study the degree of students' success achievement motivation.

Biographic questionnaire (BIV - Biographisches Inventar zur Diagnosevon Ver- 
haltenstorungen; Bottscher, Jager, Lischer) was used to study students' social level (Sozlag scale) which reflects their social success.

Abridged version of $\mathrm{KSICH}-\mathrm{B}$ (Cognitive styles of human's personality) test was used to study person's cognitive styles.

"Success" concept drawings pictorialverbal interpretation and analysis was used to define such success mental representations characteristics as the image generality level and descriptive schemes (experience structures) types. These characteristics include the variety of types of person's interaction with the entire world.

Four hundred twenty two students of Southern Federal University took part in the research.

The average age of the participants was 20 years old (19-23 years old), $51 \%$ of themmaleand $49 \%$ - female:

$1^{\text {st }}$ step - 64 students took part in the "success" concept content analysis;

$2^{\text {nd }}$ step -122 students took part in studying the "success" concept organizational styles;

$3^{\text {rd }}$ step -128 students took part in studying structural peculiarities of the success mental representations with different style predictors;

$4^{\text {th }}$ step -108 students with different success mental representations were analyzed while studying style structures.

\section{RESULTS}

First of all, the analysis of the "success" concept semantic structure was carried out. It was based on students' answers (concept generality and previous experience). Sixty four students participated in this research; they were given three minutes and offered to write as many adjectives corresponding to the "success" concept as possible.

In the course of the students' answers analysis a set of indices (signs) characterizing the "success" concept structure was recorded (purposeful, hardworking, ingenious, clever, exacting, family, sociable, friendly, and also cunning, rich, beautiful, risky, gusty, stylish, careless, etc.). Content analysis was used to systematize the obtained data. Deductive type of the qualitative and quantitative analysis was used as the basic method; it helps to define and analyze general tendencies in students "success" concept identification and its content understanding.

Modalities were defined from the ana- lyzed units in the course of a categorization; these modalities stipulated the conceptual scheme of the research.

Frequency analysis of the categories occurrence (415 categories with 555 signs/ indices characterizing the main signs of the "success" concept cognitive content) allows to note that the positive modalities of the concept prevail $(62,65 \%$ of students). In other words, most of students associate "success" with positive results of their actions (purposeful, happy, safe, etc.). However a considerable part of them $(37,35 \%)$ show negative semantic signs while analyzing the "success" concept notion (they use the following adjectives to describe success: cunning, "stopping at nothing", strange, haughty, ambitious, envious, etc.). On the one hand, these results can indicate low degree of the success image generality; on the other hand, they can be the signs of some problems students had in their previous experience. The received distribution has significant distinctions (by Fischer's angular transformation: $\left.\varphi^{*} \mathrm{emp}=7.404, \mathrm{p} \leq 0,01\right)$.

The factor analysis of frequency of the "success" concept cognitive content occurrence showed that the oftener the signs occur, the poorer their variety is (overall dispersion is $74,319 \%$ ). In this regard three groups of signs were defined: with the minimal, maximal and average occurrence frequency.

Maximal frequency of the signs occurrence corresponds to quantitative interval from 25 to 31 . Only three signs - "clever", "sufficient", "rich" (general signs amount - 87 units) are included into this group. This group is characterized by the cause and-effect signs, reflecting modern youth ideas on success results. At the same time most of students connect the notion of success with its external attribute - material component, however, they are all sure that material success as well as the success in general is possible in case of welldeveloped intelligence and intellectual potential.

Average level of occurrence frequency corresponds to an interval from 6 to 20 , and includes the bulk of the signs reflecting general tendencies in students' personal resources and features accompanying success recognizing (diligence, sociability, independence, responsibility, etc.).

The group with a low (minimal)occurrence frequency is characterized by the "success" concept cognitive content misunderstanding. Special attention is paid to the last point with a low occurrence frequency with specific semantic images of success: gold, 
phenomenal, aristocratic, fantastic, etc. It is possible to assume that young people with these associations have a low level of the success mental representation formation, brief experience and insufficient level of cognitive complexity.

The content analysis allowed defining a group of the "success" concept signs and its component structure. The research helped us to define cognitive and semantic (these indices reflect the mechanism of the intellectual and personal resources interaction providing subjects' development and semantic orientation on success: dominating index is "happiness"), regulatory and intentional components which correspond to the structure of an intellectual and personal resource (Kibal'chenko, Eksakusto, Istratova, 2017) and reflect integration of cognitive and personal opportunities of the subject. Content analysis as well reveals emotional and estimated component of the "success" concept which is characterized by such signs as beautiful, stylish, elegant, fashionable, brilliant, attractive, fine, charismatic, good, modern, big, gold, the best, fantastic, peculiar, charming, etc. All these facts allow defining emotional and significant signs of students being included into the process of own success formation.

Those specific features of the "success" concept semantic field found during the research help us to assume that there are special styles of the organization of this concept reflecting a cognitive maturity of young people.

This assumption is based on understanding the style as the way of such semantic unit of cognitive and semantic structures as a concept and its system organization and updating. The person uses style as a complex of cognitive procedures to process the knowledge and selects corresponding semantic indices on the basis of procedural and productive understanding of the concept content. This process is connected with the strategy of information processing as well as with its assessment. The concept organization style is used in conditions of the students valuable and semantic orientation system, their cognitive maturity; in case of peculiar concept cognitive structure semantic signs (in this case, "success"). These facts allow defining certain technologies of its organization. Style (its phenomenon is characterized by duality) is a backbone factor of the process mentioned above (Tolochek, 2013). The concept organization style is defined as the way of the concept internal arrangement, coherence of its differentiated signs; this style is stipulated by the subject's cognitive matu- rity and his/her ideas on the concept structure, its cognitive and semantic content.

So, the following step of the empirical research was studying the "success" concept organization styles and their distribution in the groups of students (122 persons took part).

The following "success" concept organization styles were specified as a result of quadri classification: "Accurate fast", "Accurate slow", "Inaccurate fast", "Inaccurate slow". As a result, two intervals of the signs which are hypothetically built in quadripolar analysis were received:

1) total amount of the "success" concept semantic signs (TASS), offered by the respondents in their answers (quantitative interval of signs - from 2 to 19);

2) amount of positive signs (APS), reflecting the results of the subjects' purposeful efforts in case of playing leading role, being socially recognized and having positive personal activity assessment (quantitative interval of signs - from 0 to 10 ).

These signs are considered as quadri classification axes: axis 1 - TASS and axis 2 - APS. Proceeding from results we determined the defined zero (the point of axes intersection - " 10 " by axis 1 , "5" on axis 2 ) and the "success" concept semantic signs and their styles (Picture 1).

Schematic symbols on Pic. 1:

-DZ-defined zero;

-TASS- total amount of the "success" concept semantic signs;

-APS- amount of positive signs;

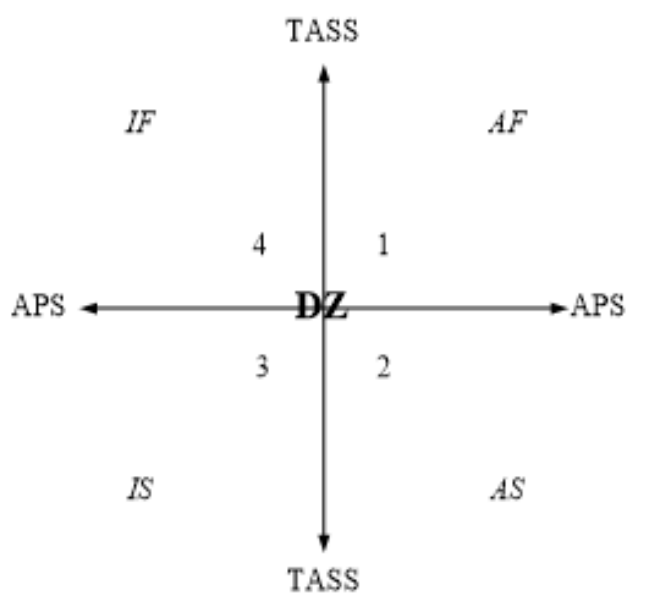

Picture 1. Model of the "success" concept cognitive content quadri classification

In our opinion the marked-out styles will be coordinated with the known cognitive styles by such criteria as quantity, quality and time; this fact is theoretically determined as follows: 
1. Accurate Fast (AF) style. Students pass the signs accurately and very fast. i.e., the students offer many signs which reflect positive results of their purposeful efforts in success achievement, as well as their social recognition and positive external assessment of their activity;

2. Accurate Slow (AS) style. Students are accurate but slow in expressing the signs of the concept. The students offer few signs of success, but these signs are essential for the "success" concept;

3. Inaccurate Slow (IS) style. Students offer few signs, indirectly related to the "success" concept cognitive content;

4. Inaccurate Fast (IF) style. Students offer many signs of the concept; however they do not reflect positive results of their purposeful efforts in success achievement, social recognition and positive external assessment of their activity.

Theoretical and empirical results show that the students' personal characteristics and cognitive styles structures are the basic ones for determinant structures of the success mental representations. That is why the third step of our research is aimed at studying stile structures of students with different success mental representations.

All the students were differentiated in accordance with their success mental representations maturity; 128 students took part in this step of the research and finally three groups of them were identified: students with poorly developed mental representations (low level: $1^{\text {st }}$ group, total number of points on criteria - 3-4); those whose mental representations are developed enough but are not perfect (average level: $2^{\text {nd }}$ group - 5-6 points); the students whose success mental representations are well-developed (high level: 3rd group 7-9 points).

The first group of students (22 persons) is characterized by specific associative representations with low generality degree (according to Kruskal-Wallis' nonparametric statistical criterion $\mathrm{H}$; for hemp. $=58.391, \mathrm{p} \leq 0,01$ ) as well as by figurative type of experience structure (identification of familiar objects and events) (hemp. $=47.975, \mathrm{p} \leq 0,01)$, i.e. they use the following adjectives to describe "success": "family", "wealth", "money", "car", "house", "career". The operational type of experience structure prevails in the second group (87 students); it is characterized by persons being constantly engaged in external world processes (hemp. $=47.975, p \leq 0,01$ ), having subject and structural images (specific sym- bolic and detailed description of success with the elements of compilation: hemp. $=58.391$, $\mathrm{p} \leq 0,01)$. The students in this group make images showing progress in cause-and-effect chains: schemes, schedules, achievement ladders (figurative models and schemes); they reflect tendency to planning, actions premeditation while goals achieving, solving various (intellectual and social) tasks. High degree of the "success" notion generality is characteristic of the third group (19 students) (hemp. $=58.391, \mathrm{p} \leq 0,01)$ : they express their feelings emotionally and in a figurative way (by drawing burning stars, fireworks, coffers with existential values). These students described rules, strategies of behavior necessary for life success achievement in different ways, paying attention to such concepts as "liberty of choice", "cronies/friends"; "spiritual, professional and personal development", etc. Positive results on the experience structure type values (hemp. $=47.975, p \leq 0,01)$ are reflected in prevalence of the operating structures (they are expressed in plans, intentions, strategies of success achieving).

Each person understands and realizes "personal success" in a different way because of the following styles peculiarities: cognitive style, activity and behavioral styles, studied on a case-by-case basis as well as on integrated level. Statistical analysis showed us significant differences between three groups on the following style characteristics: field independence (hemp. $=19.23, p \leq 0,01)$; abstract conceptualization (hemp. $=10.58, \mathrm{p} \leq 0,05$ ); self-assessment (hemp. $=7.08, \mathrm{p} \leq 0,01)$; responsibility acceptance (hemp. $=6.37$, $\mathrm{p} \leq 0,01)$.

All these variables describe mental representations specificities and their interrelations; that is why it is important to make factor analysis to reveal the success mental representations structure. The list of signs describing success mental representations was filled up with the results of success achievement motivation during interpersonal communication (additional variables correlating with success mental representations by the results of theoretical researches).

Three structures differ widely in qualitative and quantitative characteristics were found during steps of factorization and rotation (Table 1, 2, 3). 
Table 1. Components of the success mental representations factor structures in group 1

\begin{tabular}{lccc}
\hline \multicolumn{1}{c}{$\begin{array}{c}\text { Descriptive } \\
\text { characteristics }\end{array}$} & 1 & 2 & 3 \\
\hline $\begin{array}{l}\text { 1. Generalization level } \\
\text { 2. Experience } \\
\text { structures type }\end{array}$ &, 030 &, 030 &, $\mathbf{9 7 4}$ \\
\hline $\begin{array}{l}\text { 3. Achievement } \\
\text { motivation }\end{array}$ &, 431 &, 431 &, 139 \\
\hline $\begin{array}{l}\text { 4. Social status } \\
\text { 5. "Success" notion }\end{array}$ &, $\mathbf{5 1 8}$ &, 518 &,- 202 \\
\hline signs &, 103 &,- 921 &,- 042 \\
\hline Total dispersion (\%) & 26,27 & 52,54 & 72,771 \\
\hline
\end{tabular}

Table 2. Components of the success mental representations factor structures in group 2

\begin{tabular}{lccc}
\hline $\begin{array}{c}\text { Descriptive } \\
\text { characteristics }\end{array}$ & 1 & 2 & 3 \\
\hline 1. Generalization level & $\mathbf{9 9 6}$ &,- 055 &,- 047 \\
\hline $\begin{array}{l}\text { 2. Experience } \\
\text { structures type }\end{array}$ &,- 029 & $\mathbf{, 8 9 2}$ &, 159 \\
\hline $\begin{array}{l}\text { 3. Achievement } \\
\text { motivation }\end{array}$ &, 122 &,$- \mathbf{6 1 0}$ &, 573 \\
\hline $\begin{array}{l}\text { 4. Social status } \\
\text { 5. "Success" notion } \\
\text { signs }\end{array}$ &,- 117 &, 132 & $\mathbf{, 8 8 7}$ \\
\hline Total dispersion (\%) & 40,28 &,- 055 &,- 047 \\
\hline
\end{tabular}

Table 3. Components of the success mental representations factor structures in group 3

\begin{tabular}{lcc}
\hline Descriptive characteristics & 1 & 2 \\
\hline 1. Generalization level & $\mathbf{9 2 8}$ &, 301 \\
\hline 2. Experience structures type &,- 137 & $\mathbf{- , 7 6 0}$ \\
\hline 3. Achievement motivation & $\mathbf{, 8 5 9}$ &,- 253 \\
\hline 4. Social status &, 024 & $\mathbf{, 7 9 7}$ \\
\hline 5. "Success" notion signs & $\mathbf{9 2 8}$ &, 301 \\
\hline Total dispersion (\%) & 49,57 & 78,726 \\
\hline
\end{tabular}

In general, the better mental representations are formed, the higher the factor structures are developed: interaction stability increases (according to 1-1-2 variables in the last factor); degree of structure integration grows (quantity of factors: 3-3-2); variables interconnection becomes stable (1-0-0 lost connections); the quantity of factors with contradictory interrelations decreases (2-1-1).

The group with low indices of mental representations formation is characterized by prevailing of three factors (total dispersion - 72,771\%). This structure is imperfect and incomplete because such characteristic as "achievement motivation" is lost and all the indices are inconsistent and discrepant. This group can be qualified as "Cognitively simple with poor understanding of success".

The group with average values of the success mental representations formation the structure includes three factors (total dispersion $-87,025 \%$ ). The factor structure in this group is characterized by completeness, coherence, but it can also be called instable (the third factor includes only one variable). This group can be called "Cognitively mature, making sequential actions to achieve success".

The third group with high rates of the success mental representations formation the factor structure can be characterized as full, steady and coordinated. It includes two factors explaining $78,726 \%$ dispersion. This group can be defined as "Cognitively complex gunning for success".

We should pay attention to the fact that the participants' mental representations formation levels were distributed nonuniformly as a result of the research: low indices $(17 \%)$, average ones (68\%) and high ones (15\%).

The first group is characterized by cognitive simplicity of the success mental representations; this fact is determined by emotional, cognitive and behavioral "superficiality"; i.e. the participants of this group (compulsive personalities) do not tend to analyze the situation, check behavioral strategies, solve the problems, they usually make standard decisions depending on the opinion and authority of other people. Mental representations factor structures and style determinants of these students are incomplete; their indices are contradictory and uncoordinated.

The students from the second group are characterized by cognitive maturity; they are focused on positive results. All the actions are carefully thought over, planned, the goals are to be achieved; these facts help to solve cognitive and social problems and meet challenges in a step-by-step way, they also make person successful. Factor structure of success mental representations in this group is characterized by completeness, coherence, but low stability. At the same time, style determinants factor 
structure is incomplete, unstable and contradictory.

Representatives of the third group are characterized by the well-developed intellectual potential; their "success" cognitive schemes (emotional and sensual orientation, prevalence of the experience structures and existential stipulation of the "success" notion) are complex. At the same time, these students are active enough in goals achieving, use constructive strategies to solve cognitive and social tasks. Mental representations factor structures and style determinants in this group are complete, coordinated.

The fourth investigation step is aimed at analyzing such variable as the success achievement motivation. It was theoretically revealed that the success motivation is connected with a set of variables directly or indirectly defining personal success. The subjects focused on success (with average or high success achievement motivation) bear the marks of cognitive maturity, developed conceptual, representative and style abilities. We are able to assume that they have special argument-predictive structure of the "success" concept representations, peculiar cognitive models of success and experience (on the basis of which the success is formed). Using the empirical method (at the third investigation step) helped us to reveal that the worse the mental representations are formed the lower the success achievement motivation is; that is why we have to check the connection of mental representations and success achievement motivation. Success mental representation is an information complex containing objective and subjective determinants of success and its achievement. Thus, this assumption became the basis for studying success mental representations: 108 students with different success achievement motivation (SAM) took part on this step of the research.

The received distribution: 56 students $(52 \%)$ - average and average with a tendency to low success achievement motivation; 36 students $(33 \%)$ - reasonably high motivation; 16 students $(15 \%)$ - unreasonably high motivation showed that most of students entering universities (as highly intellectual subjects) are characterized by high success achievement motivation, because higher educational establishments are considered to be one of important stages of social status and social success formation. Lots of students have unreasonably high success achievement motivation; this personal characteristic cannot be called positive.

"Success" concept drawings pictorial- verbal interpretation and comparative analysis in groups with different levels of success achievement motivation showed that the success high generality degree is characteristic of the students with reasonably high motivation (16,2\% of respondents); neither the students with average level of motivation (10,1\%) nor the students with unreasonably high SAM $(0 \%)$ can be characterized by the success high generality degree. The students from this group expressed incremental advance based on cause-and-effect factors: schemes, schedules, achievement ladders (figurative models and schemes). Representatives of this group express their feelings emotionally and in a figurative way: by drawing burning stars, fireworks, coffers with existential values. This is characteristic of people with well-formed mental representations. The students with unreasonably high SAM (50\% of respondents) are characterized by low generality level of the "success" notion, whereas the students with average $(17,3 \%)$ and reasonably high $(16,2 \%)$ success achievement motivation have a normal generality level of it. $\left(\varphi^{*} \mathrm{emp} .=2.459 ; \mathrm{p}\right.$ $\leq 0,01)$.

The research is also aimed at studying the types of figurative schemes (experience structures). We found out differences in these types indices which are determined by persons' continuous and varied interaction with the world around: high values are characteristic of students with reasonably high and average SAM $(11,1 \%$ and $10,7 \%$ of respondents). Significant differences between groups are received on operational structure types reflecting the rules of information transforming: with average $(53,6 \%)$ SAM level and with the reasonably high one $(38,9 \%)(\varphi *$ emp. $=3.245$; $\mathrm{p} \leq 0,01)$; with the average level and with unreasonably high level of motivation $(12,5 \%)$ $\left(\varphi^{*}\right.$ emp $\left.=2.077 ; p \leq 0,05\right)$. The received features are complemented with significant differences in figurative schemes domination (identification of familiar objects and events) in the groups of students mentioned above: the group of students with unreasonably high motivation $(87,5 \%)$; the students with reasonably high motivation $(50 \%)\left(\varphi^{*} \mathrm{emp} .=2.822\right.$; $\mathrm{p} \leq 0,01)$, and the students with the average level $(35,7 \%)$ of SAM $\left(\varphi^{*}\right.$ emp. $\left.=2.822 ; p \leq 0,01\right)$.

All the students had to make a visual image of success and describe it verbally; but the ways of their describing rules, strategies of behavior necessary for life success achievement were different. The students with reasonably high motivation payed attention to such existential values as "liberty of choice", 
"cronies/friends"; "spiritual, professional and personal development", "health", etc. The students with unreasonably high success achievement motivation cannot be characterized by the high generality of the success "notion" or experience structure. Associative images with figurative type of experience structure (identification of familiar objects and events) prevail in this group. Such components of success as "family", "wealth", "money", "car", "house", and "career" are considered by the students in this group as the basic ones. It means that these subjects' mental representations are poorly developed (see the results of the third step of the research). These respondents perceive success as the material wealth which cannot be reached by sequential activities and appears "suddenly and on short notice". These results let usassume that the unreasonably high level of motivation is caused by superficial and simple cognitive estimation of conditions and circumstances. Such students have no strategies in their lives, do not plan their activities, they act impulsively, can be unpredictable and focused on external attributes of success that is possibly caused by cognitive simplicity of their ideas on "own success".

The analysis of the "success" concept cognitive content (modalities and signs of concept) showed the following results:

Students with different success achievement motivation have no significant discrepancy in quality of modalities while describing the "success" concept (at about 8 modalities in general; 7,7; 8,7 and 8,5 modalities in groups). At the same time $68 \%$ of students with reasonably high SAM and 39,3\% of students with average SAM level use constructive and essential signs of the concept reflecting its integrity, improving its contents $\left(\varphi^{*} \mathrm{emp}=2.603\right.$; $\mathrm{p} \leq 0,01)$. If speaking about the students with unreasonably high SAM level (25\% of them) as well as the students with reasonably high $\operatorname{SAM}(10 \%$ of them), they can be characterized by using superficial modalities (e.g. good/bad, rich/poor, simple/difficult, etc.) describing the "success" concept signs $(\varphi *$ emp. $=1.723$; $\mathrm{p} \leq 0,05$ ).

\section{DISCUSSIONS}

Quadri classification of the "success" concept cognitive and semantic signs helped to find out organization style of this concept, depending on the speed and accuracy of these signs selection, their structuring and integration. The higher the level of the students' men- tal representations maturity is, the more complete, integral and stable these representations are. The level of the students' style cognitive and personal characteristics structuredness is determinantial for the success mental representations structural organization and vice versa. These facts correspond to and elaborate such cognitive styles available data as:

- cognitive styles unify the subject's cognitive and emotional peculiarities and style systems serving as the integrators of cognitive and affective spheres of personality;

- cognitive styles are the so called "metacognitive abilities", objectifying mental representations of the events;

- cognitive styles are the characteristics determining potential of person's estimates, judgments, positions and acts objectivation as well as social behavior features (Volkova, Gusev, 2016).

Consequently, reasonably high motivation of success achievement means low frequency of superficial modalities occurrence in a "success" concept description. Such results allows speaking about significantly high cognitive maturity of the students striving for success, highly motivated on achievements, about their highly developed consciousness and being focused on gaining certain positive results and success in their lives. These results also prove the obtained data on the fact that at people with reasonably high success achievement motivation are characterized by productive and creative thinking (Fan, Wolters, 2014; Vongkulluksn et al, 2018). The students with unreasonably high motivation of success achievement use lots of categories to describe the "success" concept, but these categories are frequently often destructive for the notion integrity. i.e., these students are characterized by cognitive simplicity (estimate concepts of superficial categories as "good/bad", "pleasant/ unpleasant", "yes/no", etc.) and their intellectual immaturity (Fan, Wolters, 2014; Vongkulluksn et al, 2018). The revealed tendency to use superficial modalities (characteristic of students with unreasonably high motivation of success achievement) gives the grounds to assume that the unreasonably high level of motivation evolves from their superficial and simple cognitive estimation of all conditions and circumstances.

The received results prove that the more complete and integral the success cognitive image is, the more mature and integrated the students' personal and intellectual resources and experience are. The students having complete and integral understanding of the "suc- 
cess" concept seek for self-development, realization of the cognitive, intellectual, personal opportunities, solving various professional and life tasks and problems, they execute their functions and obligations productively and successfully. These results let us draw a parallel between our research and a well-known five-factor model of leadership and assume that the most part of students realizes connection of the success with their own experience, personal resource and own contribution as well as of subjective and objective circumstances in their lives.

\section{CONCLUSIONS}

The received results of a research allow making the following conclusions:

Students are characterized by possessing the complexes of success mental representations reflecting the world in all its forms and refracting through the identity of the subject; these representations complexes are connected with aspirations and achievements, intellectual and personal resources; the y set the procedures of personal actions, reflect and help to predict person's real and potential success.

As a result, the content analysis helped us to define a model of the "success" concept signs quadri classification. The peculiarities of this classification point to the fact that the students can be characterized by different styles of the "success" concept semantic signs organization.

Studying the aspects of the students' (the students are considered as the successful members of the modern society) intellectual and personal resources differentiation and integration offers new prospects in studying young people whose intellectual and personal features can be pegged as the explanatory principle of the subject's self-improvement and success in various spheres of activity (professional, interpersonal, personal growth, etc.).

People with high success achievement motivation are inclined to plan their future step by step and carefully; they realize and estimate their resources; make correct predictions, solve any problems and feel more satisfied, than people whose activity is aimed at avoiding failure or those whose success achievement motivation is on unreasonably high level. The subjects focused on success show the signs of conceptual and representative abilities. They are characterized by optimal level of aspirations in achieving the desirable quality of life; their "success" concept representations structure is peculiar and specific.

The students' (with different success achievement motivation) own success cognitive vision peculiarities depend on several moments. First of all, these peculiarities depend on success figurative schemes type (operational/figurative). Operational type of success figurative schemes reflects the rules of the information transforming; this type is a sign of the well-developed and mature understanding of success and is a characteristic of the students with reasonably high and average motivation of success achievement. Whereas figurative type (i.e. identification of familiar objects and events) is a sign of poorly developed understanding of success; it is characteristic of the students with unreasonably high level of success achievement motivation. These students have problems with the "success" notion understanding and generalizing. Secondly, the students' own success vision peculiarities are shown in features of the modalities used for representations creating. Thus the students with reasonably high success motivation do not use superficial modalities in their mental representations of success; they express their understanding of the "success" notion using its essential and integral signs; this fact let us consider these students as cognitively mature persons.

Thus, the more complete, complex and mature the cognitive image of success is, the more developed and integrated subject's experience, intellectual and personal resources are; in this case the students are highly motivated for self-development, implementing their personal cognitive and intellectual opportunities, reaching the success in their lives.

\section{ACKNOWLEDGEMENTS}

The article is published with financial support of the Russian Foundation of Basic Research under the scope of the scientific project No. 18-013-00029 A.

We would like to express our gratitude to Alla Belousova for consulting and collaborating with us during our writing the article. We greatly appreciate the contribution of the Psychology and Life Safety department staff as well as our colleagues from the Institute of Computer Technologies and Information Safety of the Southern Federal University in realizing the ideas pointed out in our article. 


\section{Conflict of interests}

est.

The authors declare no conflict of inter-

\section{REFERENCES}

Andrianova, E. V., Tarasova, A. N., Pecherkina, I. F. (2018). Motivation and labor values of youth: Development paradoxes. Monitoring $\mathrm{Ob}$ shchestvennogo Mneniya: Ekonomicheskie $i$ Sotsial'nye Peremeny, 145(3), 324-343. https:// doi.org/10.14515/monitoring.2018.3.17

Androsenko, M. Е. (2013). Гендерные особенности социальных представлений об успешности [Gender peculiarities of the success concept social acceptance]. The world of Psychology, 2(74), 240-246. https://elibrary.ru/item. asp? $\mathrm{id}=19034461$

Beeftink, F., Van Eerde, W., Rutte, C. G., \& Bertrand, J. W. M. (2012). Being successful in a creative profession: The role of innovative cognitive style, self-regulation, and self-efficacy. Journal of business and psychology, 27(1), 71-81. https://doi.org/10.1007/s10869-011-9214-9

Bracci, S., Caramazza, A., \& Peelen, M. V. (2018). View-invariant representation of hand postures in the human lateral occipitotemporal cortex. NeuroImage, 181, 446-452. https://doi. org/10.1016/j.neuroimage.2018.07.001

Brigley, B. J. (2018). Facilitating student performance conversations: A framework for success. Nurse Education Today. https://doi.org/10.1016/j. nedt.2018.06.008

Cigrovski, V., Radman, I., Konter, E., Očić, M., \& Ružić, L. (2018). Sport courage, worry and fear in relation to success of alpine ski learning. Sports, 6(3), 96. https://doi.org/10.3390/ sports6030096

de Haan, A. M., Smit, M., Van der Stigchel, S., Keyner, S. A., \& Dijkerman, H. C. (2018). Body representation does not lag behind in updating for the pubertal growth spurt. Journal of experimental child psychology, 175, 48-66. https://doi. org/10.1016/j.jecp.2018.05.002

Fan, W., \& Wolters, C. A. (2014). School motivation and high school dropout: The mediating role of educational expectation. British Journal of Educational Psychology, 84(1), 22-39. https://doi. org/10.1111/bjep.12002

Gervais, J., \& Cossette, P. (2007). Gestion de la connaissance et cartographie cognitive: Une étude sur la collaboration interorganisationnelle. [Knowledge management and cognitive maps: A study about interorganizational collaboration]. In $A n-$ nales des télécommunications, 62(7-8), 786807). Springer-Verlag. https://doi.org/10.1007/ BF03253290

Horvath, P. (2018). The relationship of psychological construals with well-being. New Ideas in Psychology, 51, 15-20. https://doi.org/10.1016/j.newideapsych.2018.04.008

Kholodnaya, M. A. (2004). Когнитивные стили. O природе индивидуального ума [Cognitive styles. The babes of personal intelligence]. (Vol. 2) St. Petersburg: Piter. ISBN: 5-469-00128-8. https://elibrary.ru/item.asp?id=18805704

Kibal'chenko, I.A., Eksakusto, T.V, Istratova, O. N. (2017). Интеллектуально-личностный ресурс субъекта развития: теоретические основы [Intellectual and personal resource of the subject of development: theoretical bases]. Taganrog: Southern Federal University Publ. ISBN 978-5-9275-2362-7 https://elibrary.ru/ item.asp? $\mathrm{id}=32323271$

Kibal'chenko, I. A., Eksakusto, T. V. (2016). Дескрипторы успешной предпринимательской деятельности [Descriptors of successful entrepreneurial activity]. SFEDU (Ed.) Social and humanitarian researches and technologies, 5(3), 41-46. https:// doi.org/10.12737/20936

Kishtimova, E. S. (2013). Семантика представлений о социальной успешности у молодежи [Semantics of young people success in social life perception]. Psychology in Economics and Management, 2, 128 - 130. https://elibrary.ru/ item.asp? $\mathrm{id}=22031865$

Korshunova, A. R. (2005). Аффективно-когнитивный стиль репрезентаций отнотений «Я Другой» у лии с суииидальнылми попьтками [Affective and cognitive styles of "Me-Another person" relations representations (exemplified by the people with suicidal tendencies)]. [Author's thesis dissertation in candidacy for a degree of Candidate of Psychological sciences research doctorate]. Moscow: Medical Psychology (Psychological Sciences). https://elibrary. $\mathrm{ru} / \mathrm{item} . \mathrm{asp}$ ? $\mathrm{id}=11734707$

Kuvich, G., \& Perlovsky, L. (2013). Cognitive Mechanisms Of The Mind. New Mathematics and Natural Computation, 9(03), 301-323. https://doi. org/10.1142/S1793005713400097

Low, R. S., Overall, N. C., Hammond, M. D., \& Girme, Y. U. (2017). Emotional suppression during personal goal pursuit impedes goal strivings and achievement. Emotion, 17(2), 208. https://doi. org/10.1037/emo0000218

Nanay, B. (2013). Success semantics: the sequel. Philosophical Studies, 165(1), 151-165. https://doi. org/10.1007/s11098-012-9922-7

Palmer, C. E., \& Tsakiris, M. (2018). Going at the heart of social cognition: is there a role for interoception in self-other distinction?. Current opinion in psychology. 24, 21-26. https://doi.org/10.1016/j. copsyc.2018.04.008

Pirolli, P., Mohan, S., Venkatakrishnan, A., Nelson, L., Silva, M., \& Springer, A. (2017). Implementation Intention and Reminder Effects on Behavior Change in a Mobile Health System: A Predictive Cognitive Model. Journal of medical Internet research, 19(11). https://doi.org/10.2196/ jmir.8217

Prokhorov, A. O. (2016). Mental states representations: phenomenological and experimental characteristics. Experimental psychology, 9(2), 23-37. https://doi.org/10.17759/exppsy.2016090203

Prokhorov, A.O., Alexeeva, E.M. (2017). Имплицитная ассоциативная составляющая ментальных репрезентаций психических состояний [Implicit and associative components of psychological states mental representations]. Siberia Psychological Journal, 63, 36-48. https://doi. org/10.17223/17267080/63/3

Shcherbakova, T. N., Tamaskhanova, Kh. Kh., Klad'ko A. I. (2015). Социальные представления, компетентность и успешность адаптации студентов [Students' social perceptions, competence and adaptation success]. Problems of 
Psychology. State and Municipal Management. Records of South-Caucasian Academy of Government Services (Ed.), 4, 153-157. https://elibrary.ru/item.asp? $\mathrm{id}=25137334$

Tarmaeva, V. I. (2010). Ментальные репрезентации [Mental representations]. Buryat State University Bulletin, 11, 93-98. https://elibrary.ru/item. asp?id=15237312

Thompson, T. (2004). Re-examining the effects of noncontingent success on self-handicapping behaviour. British Journal of Educational Psychology, 74(2), 239-260. https://doi. org/10.1348/000709904773839860

Tolochek, V. А. (2013). Проблема стилей в психологии: историко-теоретический анализ [The problem of psychological styles. historic and theoretical analysis]. Moscow: The Institute of Psychology of the Russian Academy of Sciences. http://толочек.pф/material/problema stiley_v_psihologii/problema_stiley_v psihologii_2013.pdf

Tsymbalyuk, A. $\overline{\mathrm{E}}$. (2011). Содержание ментальной репрезентации жизненных ситуаций в юношеском возрасте [The content of the life mental representation in youth]. Yaroslavl' Pedagogical Bulletin, 4(II), 245-248. https://elibrary.ru/item.asp?id=18235920

Tugusheva, A. R. (2008). Социальные представления и содержательные компоненты установки на успешность у молодежи [Social concepts and semantic components of the youth success motivation]. Saratov State University (named after N. G. Chernyshevskiy) transactions. Series: Psychology. Pedagogics, 2(3-4), 42-44. https:// elibrary.ru/item.asp?id $=15133751$

van Rooij, E. C., Jansen, E. P., \& van de Grift, W. J. (2018). First-year university students' academic success: the importance of academic adjustment. European Journal of Psychology of Education, 1-19. https://doi.org/10.1007/s10212-017-03478

Volkova, N. N., Gusev, A. N. (2016). Когнитивные стили: дискуссионные вопросы и проблемы изучения [Cognitive styles: Controversial issues and research problems]. National Psychological Journal, 2, 28-37. https://elibrary.ru/ item.asp? $\mathrm{id}=27536968$

Vongkulluksn, V. W., Matewos, A. M., Sinatra, G. M., \& Marsh, J. A. (2018). Motivational factors in makerspaces: a mixed methods study of elementary school students' situational interest, self-efficacy, and achievement emotions. International Journal of STEM Education, 5(1), 43. https:// doi.org/10.1186/s40594-018-0129-0

Welsch, D. M., \& Zimmer, D. M. (2018). Do High School Gifted Programs Lead to Later-in-Life Success?. Journal of Labor Research, 39(2), 201-218. https://doi.org/10.1007/s12122-0179252-9

Welsch, David M., Zimmer, David M. (2018). Do High School Gifted Programs Lead to Later-in-Life Success? Journal of labor research, 39(2), 201218. https://doi.org/10.1007/s12122-017-92529 